\title{
Time of transition
}

\author{
Max Aebi · Robert Gunzburg
}

Received: 14 May 2014/Revised: 14 May 2014/Accepted: 14 May 2014/Published online: 27 May 2014

(C) Springer-Verlag Berlin Heidelberg 2014

The first journal focusing on spine-SPINE—was founded 38 years ago by Henry LaRocca in the USA. Twelve years later, this journal had an offspring in form of the "Journal of Spinal Disorders and Techniques", targeting more surgical techniques and practice than basic science. Although the 80 s of last century became unprecedented in terms of development of new technologies in spine surgery, mostly coming out of Europe, there was no European scientific journal focusing on spine. Spine-related articles were mostly published in general orthopaedic journals. To give the spine sciences and surgery in Europe its own face, the European Spine Journal was founded by Springer in 1991, under the impulse of Max Aebi who became Editor-inChief. By the turn of the 20th into the 21st century, there were five major journals with an exclusive focus on spine sciences.

About the same time as the launching of the ESJ-a real pioneering time-the European Spine Society was independently founded. It later merged with the European Spinal Deformity Society to form the Spine Society of Europe.

From the first, the European Spine Journal choose to be a platform for bringing together clinicians and scientists from across all disciplines. Whereas European at its inception, it soon became attractive to many individuals and scientific societies outside Europe. This broad base of

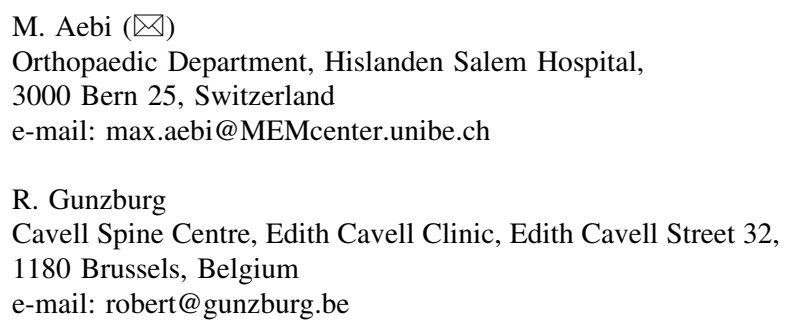

interest is mirrored at the level of the Editorial Board where clinicians and scientists from societies all over the world figure.

The European Spine Journal developed its own identity with diverse assets: next to the regular issues with original papers, review articles and case reports, there came "grand rounds" and cinematographic material. The European Spine Journal certainly did not miss the advent of the e-age. It also offers supplements as focus issues in specific fields and subspecialties, and as platform for individual national spine societies.

The ever increasing number of medical publications presents a significant challenge for the individual practitioner who wants to choose the correct and relevant information. The future success of journals will greatly depend on the way this challenge is addressed.

With the European Spine Journal at the brink of transfer of the editorial responsibility from the Editor-in-Chief of the last 23 years to the next one, the post was opened to applicants via a large international appeal for candidatures. There will be a smooth and progressive transition period, with Max Aebi initially staying active in the Editorial Board. The challenges ahead will require commitment and creative solutions and we are confident that the new Editorin-Chief, together with Springer, the Advisory and Editorial Boards as well as the readership, will drive the European Spine Journal further on its upwards course.

Max Aebi

Editor-in-Chief (1991-2014)

Robert Gunzburg

Editor-in-Chief (from 2014 on)

Conflict of interest None of the authors has any potential conflict of interest. 